\title{
Quality of life predictors in informal caregivers of seniors with a functional performance deficit - an example of home care in Poland
}

This article was published in the following Dove Press journal:

Clinical Interventions in Aging

\section{Barbara Ślusarska \\ Agnieszka Bartoszek \\ Katarzyna Kocka \\ Alina Deluga \\ Agnieszka Chrzan-Rodak (1D \\ Grzegorz Nowicki}

Department of Family Medicine and Community Nursing, Faculty of Health Sciences, Medical University of Lublin, Lublin, Poland
Correspondence: Agnieszka Chrzan-Rodak Department of Family Medicine and Community Nursing, Faculty of Health Sciences, Medical University of Lublin, Street Staszica 4-6, 20-08I Lublin, Poland

Tel +4 88I 4486810

Fax $+488 I 448$ 68II

Email agnieszkachrzan607@gmail.com
Background: There is insufficient research into informal caregivers' quality of life (QoL) in Poland. The purpose of this work is to study predictors that considerably affect QoL of informal caregivers (IC) providing home care for seniors with chronic diseases and a functional performance deficit.

Materials and methods: In the cross-sectional research design, ICs were randomly chosen among the geriatric population receiving care in 5 primary health care settings. The WHOQoL-AGE questionnaire was used to assess QoL of ICs $(n=138)$. The Barthel scale and Polish version of the Abbreviated Mental Test Score (AMTS) were applied to assess individuals with chronic diseases and functional and mental performance deficits $(n=138)$. The Geriatric Depression Scale Short Form (GDS-SF) was used to measure the extent of risk of depressive symptoms in care-receivers. A hierarchical regression analysis was carried out to determine predictors of caregivers' QoL.

Results: Mean values in the group of seniors provided with home care were as follows: the Barthel scale $\mathrm{M}=43.20, \mathrm{SD}=27.06$, the AMTS $\mathrm{M}=7.78(\mathrm{SD}=1.65)$, and the GDS-SF $\mathrm{M}=7.34$ $(\mathrm{SD}=3.10)$. QoL of ICs (the WHOQoL-AGE) was $\mathrm{M}=70.14$ ( $\mathrm{SD}=15.31$ ). Significant predictors of caregivers' QoL turned out to be support in care given by others $\beta=0.605$, $p<0.001$, experience in care $\beta=0.220 ; p<0.001$, caregivers' health self-assessment $\beta=0.174, p<0.001$, and depressive disorders in care-receivers GDS $\beta=-0.178, p<0.001$.

Conclusions: The QoL of ICs who provide care for individuals with chronic diseases and a functional performance deficit improves with an increase in the support they receive from others, their higher health self-assessment, and greater experience in care. An increase in depressive symptoms in care-receivers determines a lower level of caregivers' QoL.

Keywords: predictors, informal caregivers, quality of life, home care, functional performance deficit, patients with chronic diseases

\section{Introduction}

According to official prognoses, the population of elderly people aged 65 years or more will increase from $87.5 \mathrm{mln}$ in 2010 to $152.6 \mathrm{mln}$ in 2060 in the European Union (EU). Therefore, there will be a surge in pensioners from $14.0 \%$ in 2015 to $27.8 \%$ in 2060 European Commission Directorate-General for Economic and Financial Affairs. ${ }^{1}$ In Poland, the population of the elderly will grow to $33 \%$ by 2060 Eurostat news release ${ }^{2}$ and people over 80 years of age will constitute the main beneficiaries of care services exceeding a threshold of $12 \%$ in $2060 .^{3}$ This demographic trend shows a dynamic increase in demand for services of long-term 
care, mainly concerning a growth in the number of the elderly requiring care in their homes. ${ }^{4}$ The provision of complex formal and informal environmental care that could make the stay of the elderly at home possible constitutes a great challenge in the world. ${ }^{5-7}$ Many authors claim that despite increasing dependency on paid longterm care for the elderly, informal care remains the most common form of long-term care provided both in the $\mathrm{USA}^{8,9}$ and in Europe. ${ }^{10,11}$

The provision of long-term informal care of patients with chronic diseases and low functional performance results in many consequences for informal caregivers, such as psychic, physical and material burden. ${ }^{12,13}$ The risk of death also increases among them. ${ }^{14}$

According to the definition of an informal caregiver (IC), this is a person who provides regular, permanent, physical and (or) emotional support and assistance with activities of daily living (ADLs) for somebody who is physically or mentally disabled, mentally ill or is an elderly person whose physical and mental condition is poor. ${ }^{15}$

In the EU countries, on average $3-4 \%$ of the people aged over 65 are provided with long-term institutional care. ${ }^{16}$ In Poland, current solutions regarding long-term care and ways of funding it are not sufficiently appropriate for the needs of the aging society. ${ }^{17}$ According to the data of the Central Statistical Office (CSO), the percentage of seniors aged 75 years old and more living in different types of social welfare nursing homes (including those also providing therapeutic services) does not exceed $1.5 \%$. ${ }^{18}$ Poland has the lowest number of beds per 1,000 patients in long-care settings, compared to other countries of the Organisation for Economic Co-operation and Development (OECD). The percentage of people who do not receive institutional care or home care in Poland is still the highest among the EU countries. ${ }^{19}$

In Poland, family is still a rudimentary "caring institution" acting in order to help/support the elderly. ${ }^{20,21}$ SzturJaworska $^{24}$ says that on the basis of Pol-Senior research results, the closest family members (mainly children) is the most important source of help for the elderly. The role of people from outside the circle is minor and the most obvious in the case of the psychic support. The potential of help provided by representatives of helping professions (a carer, community nurse, social worker) is perceived by the elderly as marginal one, which shows that in the case of life difficulties they do not see alternative care different from their family. ${ }^{22,23}$ The major role of family care for the elderly results from traditional commitment of the family to the provision of care for their close relatives (associated with cultural conditions) and the specific phase of economic development Poland is found in as well as restricted possibilities of getting care from outside a family. ${ }^{24}$

An increase in a demand for health services in home care generates the necessity of combining both formal and informal care for care-receivers. One of the forms of formal home care in the Polish health care is long-term care provided by nurses. Individuals staying in their home environment have the right to this care if they obtain assessment of $0-40$ points according to the Barthel scale and a referral for such care from their General Practitioners. Apart from that, those individuals with chronic diseases and a functional performance deficit are provided with care by ICs.

In Poland, there has been insufficient research into QoL of ICs and organizational frameworks for ICs' interventions. Our study refers to selected elements of organizational frameworks worked out by Van Houtven et al They included the Caregiver and Care Recipient Baseline Characteristics (demographic data, health condition, type of relationship), Caregiving Activities (search for support and quantity of care), Caregiver Outcomes (mental health), Care Recipient Outcomes (tasks associated with disease management skills). ${ }^{8}$

In Poland, the research conducted so far has focused mainly on the results regarding caregivers and burden of care $^{25-29}$ and the results of care-recipients (patients). ${ }^{30}$ Fewer studies concerned caring activities. ${ }^{31,32}$

The review of the research data available shows that in Poland this is the first study by means of WHOQoL-AGE among ICs of the elderly with chronic diseases and a functional performance deficit getting home care. So far, Gawlik et al have conducted research into the assessment of QoL of ICs looking after patients with neoplasms by means of the Caregiver Quality of Life Index-Cancer (CQOL-C). ${ }^{25}$ Other authors studied burden of ICs connected with the provision of care for people suffering from Alzheimer's disease and they used the Geriatric Depression Scale (GDS), the Hopelessness Scale, the Perceived Stress Scale, the Satisfaction for Life Domains Scale, Polish version of the Caregiver Burden Scale (CB Scale). ${ }^{12,29}$ Karczewska et $\mathrm{al}^{33}$ researched burden of ICs taking care of the elderly with dementia and cognitive impairment using the Common Assessment Tool, while Grochowska $^{34}$ assessed the sense of satisfaction and burden of ICs applying the author's own questionnaire.

Literature provides essential evidence of the fact that ICs are hidden patients who need protection against 
physical and emotional consequences that result from burden of home care they provide. ${ }^{35-37}$

\section{The aim of the study}

The purpose of the work was the determination of predictors having the greatest influence on quality of life of ICs who take care of individuals with chronic diseases and a functional performance deficit in a home environment.

\section{Material and methods Study design}

In the study, a cross-sectional mixed-methods design was applied in order to assess two domains of parameters in dyads related to (1) ICs, (2) patients with chronic diseases and a functional performance deficit who receive informal care in a home environment. For the purpose of this work, we focus only on the presentation and analysis of the data coming from the protocol of ICs' assessment.

In the cross-sectional study, ICs were researched randomly among the geriatric population who receive care in Primary Health Care (PHC) settings. On the basis of the data available in the PHC settings PHC, 324 dyads were found, namely patients being cared for by ICs in their home environment who met the inclusion criteria both for patients and their caregivers. The study included every second person from the list of care-receivers generated. Finally, 155 dyads were qualified for the research (care-receivers who were looked after by ICs) because 14 cases did not consent to the participation in the study (Table S1).

\section{Participants and setting}

This cross-sectional study was carried out from September 2016 to February 2017 in the Lublin Region in Eastern Poland. The study encompassed a group of 155 ICs and 155 care-receivers staying in their home environment who had a functional performance deficit. The inclusion criteria for the ICs were as follows: being an IC of an individual aged 60 and more with a chronic disease and functional performance deficit who stayed in their home environment. The inclusion criteria to be met by the patients were as follows: (1) living at home, (2) having a functional performance deficit based on the Barthel scale of 0-85 points, (3) not having cognitive impairment measured by means of the AMTS $>6$ (the Abbreviated Mental Test Score), (4) not having blindness/deafness, (5) not having serious communicative disabilities, (6) being able to express informed consent or consent consistent with their cognitive capacity level, (7) not having behaviour disorders such as severe aggression, behaviours that enable a person to fill in a questionnaire and perform anthropometric measures or impulsive behaviours. The study sample of 138 ICs and 138 patients of both sexes staying in their homes was included. In total, we excluded 17 ICs and 17 patients because of lack of one or more replies in the questionnaires ( $\mathrm{n}=5$ cases), patients' or ICs' resignation from participation in the study $(\mathrm{n}=7)$, change of place of residence $(\mathrm{n}=2)$ and a situation when a patient was moved to an institutional care home $(n=3)$ (Figure 1).

\section{Procedure}

The data from the ICs and care-receivers were collected in a direct interview conducted by community nurses $(n=18)$

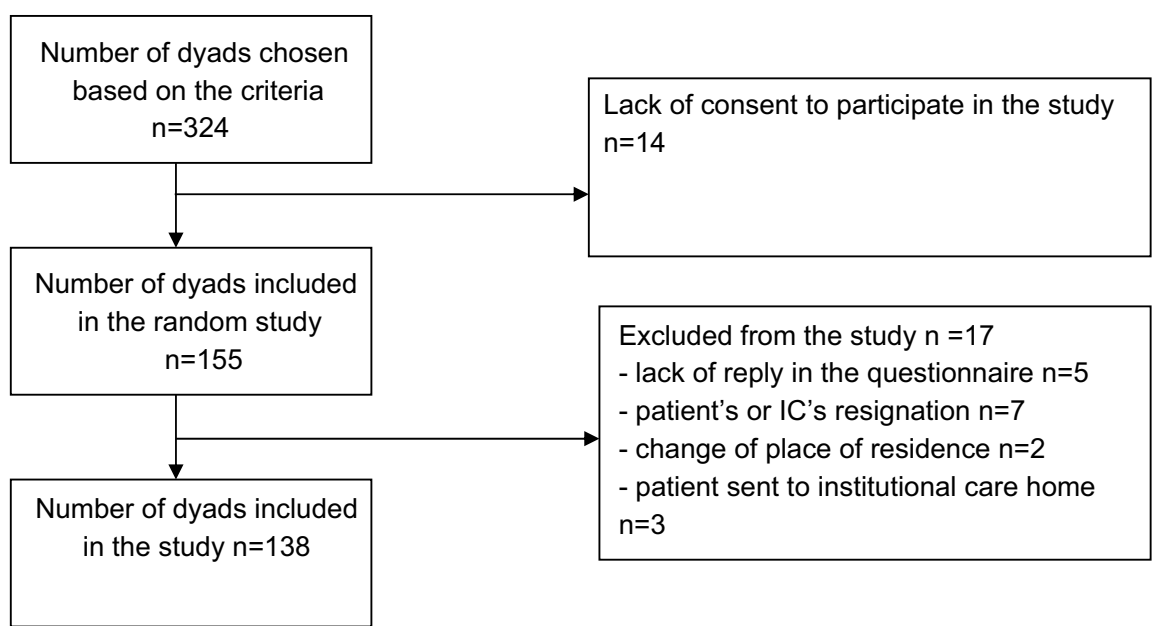

Figure I Flow chart of the dyads.

Abbreviations: $n$, numbers of dyads; IC, informal caregiver. 
during home visits (Table S1). The condition to be met by a nurse to take part in the study as a person collecting the data was at least 5-year experience in community care. The nurses were employed in 5 health care settings ( 4 in urban areas, and 1 in a rural area). Prior to the interview, the nurses had been informed about the research project and undergone training on the way of selecting ICs and patients for this study and completing the questionnaires based on the research procedure assumed. One day before the interview, a nurse called the respondents to make an appointment with an IC and their patient. All necessary actions were taken to guarantee the participants' anonymity and confidentiality of information. The participants (both ICs and their patients) gave written informed consent to the study participation. The research material was collected at home where the patient stayed. In order to ensure control and correctness of the process of collecting the data, every tenth dyad was accompanied by a person from the research team who confirmed the quality of the data provided.

\section{Instruments}

\section{Research tools in the assessment of ICs}

The data on ICs' QoL were collected by means of a standardized tool by previously trained community nurses. All the ICs also replied general questions regarding their social and demographic situation.

The WHOQol-AGE questionnaire was applied to assess aspects of QoL of elderly ICs ( $>60$ years). This tool, compiled by Cabarello et al $^{38}$ in 2013 then adjusted and validated to Polish conditions by Zawisza et $\mathrm{al}^{39}$ consists of 12 items classified into two subscales: F1 satisfaction and F2 - expectations fulfilment, as well as one item regarding self-assessment of QoL, with the following categories of replies (very poor; poor; neither poor nor good; good; very good). The subscale F1 includes 7 items and measures satisfaction with performance of the sense organs, health condition, oneself, one's ability to perform ADLs, individual relationships, conditions in one's place of residence and ways of spending free time. The subscale F2 comprises 5 items and checks expectations fulfillment and/or one's ability of performing some activities such as sufficient energy for daily living, controlling of what an individual would like to do, possibility of achieving goals intended, sufficient money for meeting the individual's needs, and satisfaction with having close friendships. The scale assesses the level of QoL in the range from 0 to 100 where those higher scores show higher level of QoL. The final score is the arithmetical mean of the two subscales (domains). The WHOQoLAGE questionnaire is an accurate and reliable tool for assessing QoL of aging populations. It was worked out as part of the Collaborative Research on Aging in Europe Project (COURAGE in Europe) and approved in Finland, Poland and Spain. The Cronbach's alpha coefficient for the Polish sampling was $0.91 .^{38,39}$

\section{Demographic and social variables}

The socio-demographic data collected describing the group of ICs included: gender (female or male), age, marital status (single or in a relationship), place of residence (urban or rural areas) and type of relation to a carereceiver (spouse, child, sibling, son-in-law/daughter-inlaw, distant relation or lack of kinship/friend/neighbour) and distance from the IC's place of residence to the carereceiver's. The variables that were taken into account to assess the IC's care of a care-receiver were as follows: experience in care, mean duration of care for a carereceiver (years) and mean duration of care for a carereceiver provided weekly (hours). At the end of the interview, a person who was collecting the data asked an IC to assess his or her health (very good, good, mediocre, poor or very poor) and support in care provided by other people (Apart from you are there any other people who help you to provide continuous care for a care-receiver at home? Yes/No).

Research tools for the assessment of the elderly with chronic diseases and a functional performance deficit The patients' data were collected using the standardized clinical interview conducted by previously trained community nurses during home visits. General data on sociodemographic variables were collected from all the patients.

The Barthel scale was applied to assess functional performance, namely an ability to perform basic daily activities and necessity for receiving help from others to have the activities done. The scale focuses on the assessment of ADLs such as having meals, movement, grooming, toilet use, bathing, walking, climbing stairs, dressing, bladder and bowel control. Points from 0 to 100 are assigned to individuals depending on their independence. The score obtained shows their disability and describes their condition and need for help. Their capability may be differentiated in relation to the range of points obtained. They can be qualified for the following groups: individuals who deal with ADLs well obtain 86-100 points; those who do not deal with ADLs partially obtain 
21-85 points; those who are unable to cope with most ADLs on their own receive $20-0$ points. ${ }^{40}$ The usefulness of the Barthel scale for Polish healthcare as a reliable tool $(\alpha-$ Cronbach's coefficient $=0.78 \div 0.89$; test-retest correlation coefficient $\mathrm{R}=0.93 \div 0.95$ ) used for measuring the range of seniors' independence in ADLs has been confirmed in many studies. ${ }^{41}$

The Abbreviated Mental Test Score (AMTS) which consists of 10 questions was used to assess mental capacity, namely cognitive impairment and its severity. If a person replies to a question appropriately, he or she gets 1 point. The maximum score is 10 points, and the minimum one is 0 . Based on their score, people are qualified for one of three possible degrees of mental capacity. The score of 7-10 points means a good condition, the score of 4-6 points shows moderate cognitive impairment while the score of $0-3$ points indicates severe cognitive impairment. ${ }^{42}$

The Polish version of the Geriatric Depression Scale Short Form (GDS-SF) ${ }^{43}$ was utilized to screen for depressive symptoms. It was compiled to check for severity of depression symptoms. ${ }^{44}$ The scale comprises 15 items where a patient confirms or denies (Yes/No) the presence of symptoms within the previous 2 weeks. The number of points obtained shows lack of depression ( $0-5$ points) or risk of depression (6-15 points). The reliability of the scale was measured by Cronbach's alpha coefficient which amounted to 0.86 .

\section{Demographic and clinical variables}

The sociodemographic data describing the group researched were gender and age. The variable taken into account in the medical assessment was having multiple diseases, i.e. the presence or absence of cardiovascular, respiratory, endocrine, nervous, mental, locomotor diseases and diseases of the senses - based on the ICD-10.

\section{Bioethic requirements for the study}

A written consent to the study was granted by the managers and directors of the health facilities, where the nurses performing the research were employed. Each IC and care-receiver was orally informed by the nurses regarding the objective of the study, and the scope of the questionnaires, measurements, and then a written consent was taken. The study was voluntary and anonymous. Nurses completed the questionnaires during an interview and provided the participants with necessary information and explanation. During each stage of the data collection, the participants could resign or refuse further participation in the study. The study procedure implemented was approved by the Bioethics Committee of the Medical University of Lublin (no KE-0254/13/2016) and was consistent with the Declaration of Helsinki. The study was realized in the frame of own research, financed by the Medical University of Lublin.

\section{Statistical analysis}

The statistical analysis was carried out using IBM SPSS Statistics 20 software. Descriptive statistics such as frequency, percentage, mean (M), median (Me) and standard deviation (SD) were used to describe the basic features of the data in the study. The Pearson correlation coefficient (r) was used to check the correlation between variables on a quantitative scale. Prior to the application of the coefficient, the distribution of variables was analyzed: skewness and kurtosis ranged $(-1 ; 1)$. For ordinal variables and those whose distributions did not meet conditions for the use of Pearson's r, the Spearman's rho correlation coefficient was applied. The point-biserial correlation coefficient was utilized to determine correlation between a quantitative variable and dichotomic one. The determination of the correlation between a quantitative variable and a nominal and dichotomic variables was performed on the basis of multiple regression analysis with step introduction of exploratory variables; though, distributions of variables were checked first: skewness and kurtosis of the distributions ranged $(-1 ; 1)$. The model of regression is applied when some correlations between predictors and a dependent variable can be assumed and allows the conclusion of whether adding some variables may improve the quality. ${ }^{45}$ Statistical significance was assumed $p<0.05$.

\section{Results}

\section{Characteristics of ICs}

The majority of the caregivers were females $(77.5 \%)$. The mean age of the study group was 68.57 years $(\mathrm{SD}=11.6)$. The youngest caregiver was 60 years old and the oldest one was 84 years old. The largest group of caregivers (44.2\%) was composed of individuals 66-75 years of age. The oldest caregivers being 75 and more constituted $14.5 \%$. Most of the ICs $(69.6 \%)$ were married/in a relationship. The caregivers who looked after carereceivers with chronic diseases and a functional performance deficit were mostly spouses $(43.5 \%)$, then children $(23.2 \%)$. Caregivers who were not relatives constituted $19.6 \%$ of the respondents studied. More than half of the caregivers $(51.4 \%)$ was not professionally active and their 
main source of income was disability or old age pension. Among the professionally active caregivers, $18.1 \%$ of them had full-time jobs and $19.6 \%$ had part-time jobs. Slightly above half of the caregivers $(50.7 \%)$ had previous experience in looking after the elderly and $44.2 \%$ of them were first-time caregivers.

The mean number of hours per week devoted to home care for an individual with low functional performance was $36.24 \mathrm{hrs}(\mathrm{SD}=41.15)$. Over half of the respondents researched $(52.9 \%)$ were the only caregiver with no support in care provided by others. A total of $47.1 \%$ of the caregivers were supported by others, with a mean of 20.78 $(\mathrm{SD}=26.2)$ hours weekly. Most of the caregivers (60.9\%) lived with their care-receivers in the same flat. Most of the caregivers assessed their health condition as good (42.8\%). A low percent of the caregivers $(8.7 \%)$ assessed their health as poor and a total of $1.4 \%$ as very poor. Detailed socio-demographic characteristics of the caregivers are given Table 1.

\section{Characteristics of the care-receivers being looked after by ICs}

The group of chronically ill individuals with a functional performance deficit $(n=149)$ receiving long-term home care consisted of $76.5 \%$ of women and $23.5 \%$ of men. Their age ranged from 58 to 104 years old, the mean age was 74.91 ( $\mathrm{SD}=9.08)$. The mean period of getting home care was 3.59 years $(\mathrm{SD}=2.68)$. According to the Barthel scale, the range of functional performance deficits was from 0 to 85 points, while the range of mental capacity was from 0 to 10 points on the basis of the AMTS. The mean values of functional performance and mental capacity were $\mathrm{M}=43.20, \mathrm{SD}=27.06$ for the Barthel scale and $\mathrm{M}=7.78$ ( $\mathrm{SD}=1.65$ ) for the AMTS. Consistent with the Barthel scale, functional performance was low (21-40 points) in the largest group - 63 individuals (45.6\%) and very low (0-20 points) in 45 individuals (32.9\%). Moderate functional performance (41-85 points) was found in 30 people $(21.5 \%)$. The assessment of the risk of depression based on the GDS-SF showed the mean value of 7.34 points $(S D=3.10)$ in the group of the carereceivers studied.

The care-receivers researched had multiple diseases; rheumatoid ones were dominant $(77.9 \%)$, diseases of the senses constituted $65.1 \%$, mental disorders $51.7 \%$ and endocrine conditions amounted to $45 \%$. Detailed sociodemographic characteristics of the care-receivers are given in Table 2.

\section{QoL of ICs according to the WHOQOL-AGE}

The group of ICs researched assessed their QoL as high at a level of $\mathrm{M}=70.14(\mathrm{SD}=15.31)$ on the basis of the WHOQoL-AGE. The subscale F1 - satisfaction, obtained higher mean scoring in the group $\mathrm{M}=71.11$ ( $\mathrm{SD}=13.88$ ) than the subscale $\mathrm{F} 2$ - expectations fulfillment, $\mathrm{M}=69.159$ $(\mathrm{SD}=18.55)$. The results are shown in Figure 2.

\section{Predictors of conditions for ICs'QoL}

Hierarchical regression analysis was utilized to determine predictors of conditions for caregivers' QoL. For the explanatory variable of the WHOQoL-AGE in the first block of variables, the following independent indicators were assumed: gender, age, marital status, kinship, distance from the care-receiver, support in care given by others. In the second block, the independent variables were associated with the care of the care-receiver and they were as follows: duration of care, caregiver's health self-assessment, experience in care. The variables that describe care-receivers' health condition (the AMTS, GDS-SF, Barthel's) were used as independent variables in the third block. The results are shown in Table 3 (Table S2)

In the first block of variables, a significant predictor in the stepwise regression analysis was the support provided for the caregiver by other people. The model turned out to be well adjusted to the data and explained $37.0 \%\left(\mathrm{R}^{2}\right.$ adjusted $\left.=0.37\right)$ of variance of explanatory variable $\mathrm{F}(1.118)=71.693 ; p<0.001$. In the second step of regression analysis, another predictor, namely experience in care, was included, in the explanatory variables significant for this model, which resulted in explaining $40 \%$ ( $\mathrm{R}^{2}$ adjusted $=0.40$ ) of the variance in the condition of the support provided $\mathrm{F}(2.117)=41.345 ; p<0.001$. As far as the third step of regression analysis is concerned, the introduction of another variable - caregivers' health self-assessment resulted in explaining $43 \%\left(\mathrm{R}^{2}\right.$ adjusted $\left.=0.43\right)$ of variance of the variable explained F (3.116)=31.107; $p<0.001$. Another independent variable added in the fourth step of the analysis was the assessment of depressive symptoms GDS in carereceivers, which resulted in explaining $46 \% \quad\left(\mathrm{R}^{2}\right.$ adjusted $=0.46$ ) of variance within the condition of caregivers' QoL F (4.115)=26.207; $p<0.001$. The aforementioned results of the multivariable multiple regression confirm that the model was adjusted appropriately and significant predictors of the ICs'QoL, among the initially introduced ones, turned out to be the support provided by other people $\beta=0.605 ; p<0.001$; experience in care $\beta=-0.220 ; p<0.001$, ICs' health assessment 
Table I Social and demographic characteristics of the IC $(n=\mid 38)$

\begin{tabular}{|c|c|}
\hline Caregivers' social and demographic features $(n=$ significant) & All participants $(n=138)$ \\
\hline \multicolumn{2}{|l|}{ Sex } \\
\hline Female & $77.5(107)^{\mathrm{a}}$ \\
\hline Male & $22.5(31)^{\mathrm{a}}$ \\
\hline \multicolumn{2}{|l|}{ Age (years old) } \\
\hline $60-65$ & $41.3(57)^{\mathrm{a}}$ \\
\hline $66-75$ & $44.2(6 I)^{\mathrm{a}}$ \\
\hline Over 75 & $14.5(20)^{\mathrm{a}}$ \\
\hline \multicolumn{2}{|l|}{ Mean age (years old) [age range: $60-84$ years old] } \\
\hline Civil status & $68.57 \pm 11.6,66.5^{\mathrm{b}}$ \\
\hline Single & $30.4(42)^{\mathrm{a}}$ \\
\hline Married/in a relationship & $96.9(96)^{\mathrm{a}}$ \\
\hline \multicolumn{2}{|l|}{ Relation to a care-receiver } \\
\hline Spouse & $43.5(60)^{\mathrm{a}}$ \\
\hline Child & $23.2(32)^{\mathrm{a}}$ \\
\hline Sibling & $4.3(6)^{\mathrm{a}}$ \\
\hline Daughter-in-law/son-in-law & $5.1(7)^{\mathrm{a}}$ \\
\hline Further family & $4.3(6)^{\mathrm{a}}$ \\
\hline Lack of kinship/friend/neighbour & $19.6(27)^{\mathrm{a}}$ \\
\hline \multicolumn{2}{|l|}{ Caregiver's professional activity } \\
\hline Full-time & $18.1(25)^{\mathrm{a}}$ \\
\hline Part-time & $19.6(27)$ \\
\hline Job order contract & $4.3(6)^{\mathrm{a}}$ \\
\hline Retired/pensioned & $5 I .5(7 I)^{\mathrm{a}}$ \\
\hline Unemployed & $6.5(9)^{\mathrm{a}}$ \\
\hline \multicolumn{2}{|l|}{ Place of residence } \\
\hline Urban areas & $93.5(129)^{\mathrm{a}}$ \\
\hline Rural areas & $6.5(9)^{\mathrm{a}}$ \\
\hline \multicolumn{2}{|l|}{ Distance from the caregiver's place of residence to the care-receiver's } \\
\hline The same flat & $60.9(84)^{\mathrm{a}}$ \\
\hline The same building & $8.7(12)^{\mathrm{a}}$ \\
\hline A short-walk distance & $10.9(15)^{\mathrm{a}}$ \\
\hline About 10 min distance by means of transportation & $11.6(16)^{\mathrm{a}}$ \\
\hline About 30 min distance by means of transportation & $6.5(9)^{\mathrm{a}}$ \\
\hline About 60 min distance by means of transportation & $0.7(1)^{\mathrm{a}}$ \\
\hline Over 60 min distance by means of transportation & $0.7(1)^{\mathrm{a}}$ \\
\hline \multicolumn{2}{|l|}{ Experience in care } \\
\hline The first person being taken care of & $44.2(6 \mathrm{I})^{\mathrm{a}}$ \\
\hline A consecutive person being taken care of & $50.7(70)^{\mathrm{a}}$ \\
\hline Daily work with patients receiving home care & $4.4(6)^{\mathrm{a}}$ \\
\hline Specialized course for medical caregivers & $0.7(I)^{\mathrm{a}}$ \\
\hline Mean duration of care of a care-receiver (years) & $3.59 \pm 2.68,3.1^{\mathrm{b}}$ \\
\hline $\begin{array}{l}\text { Mean duration of care of a care-receiver provided weekly } \\
\text { by an IC (hours); }(n=138)\end{array}$ & $36.24 \pm 41.15,32.0^{b}$ \\
\hline Mean duration of care of a care-receiver provided weekly & $20.78 \pm 6.2,17.5^{b}$ \\
\hline \multicolumn{2}{|l|}{ by individuals supporting caregivers (hours); ( $n=72)$} \\
\hline \multicolumn{2}{|l|}{ Support for ICs provided by other people } \\
\hline No & $52.9(73)^{\mathrm{a}}$ \\
\hline Yes & $47.1(65)^{\mathrm{a}}$ \\
\hline
\end{tabular}

(Continued) 
Table I (Continued).

\begin{tabular}{|l|l|}
\hline Caregivers' social and demographic features $(\mathbf{n}=$ significant) & All participants $(\mathbf{n}=\mathbf{I 3 8})$ \\
\hline Health self-assessment & $12.3(17)^{\mathrm{a}}$ \\
Very good & $42.8(59)^{\mathrm{a}}$ \\
Good & $34.8(48)^{\mathrm{a}}$ \\
Mediocre & $8.7(12)^{\mathrm{a}}$ \\
Poor & $1.4(2)^{\mathrm{a}}$ \\
Very poor & \\
\hline
\end{tabular}

Note: Data are presented as ${ }^{a} \mathrm{n}(\%) ;{ }^{b}$ mean $\pm S D$, median.

Abbreviation: IC, informal caregiver.

Table 2 Social and demographic characteristics of the care-receivers being looked after by informal caregivers (ICs) $(n=\mid 38)$

\begin{tabular}{|l|l|}
\hline Variables & $\begin{array}{l}\text { All participants } \\
(\mathbf{n}=138)\end{array}$ \\
\hline Sex & \\
Male & $23.9(33)^{\mathrm{a}}$ \\
Female & $105(76.1)^{\mathrm{a}}$ \\
Age (years) [age range: 58-I04 years old] & $74.91 \pm 9.08,74.4^{\mathrm{b}}$ \\
Functional capacity according to & $43.2 \pm 27.06,32.4^{\mathrm{b}}$ \\
Barthel index & \\
0-20 points & $32.6(45)^{\mathrm{a}}$ \\
2I-40 points & $45.7(63)^{\mathrm{a}}$ \\
4I-85 points & $21.7(30)^{\mathrm{a}}$ \\
Geriatric Depression Scale - Short & $7.34 \pm 3.1,7.1^{\mathrm{b}}$ \\
Form (GDS-SF) & \\
0-5 points & $44.2(61)^{\mathrm{a}}$ \\
6-I5 points & $55.8(77)^{\mathrm{a}}$ \\
Abbreviated Mental Test Score (AMTS) & $7.78 \pm 1.65,7.6^{\mathrm{b}}$ \\
>6 points & $100(138)^{\mathrm{a}}$ \\
Multimorbidities (according to ICD) & \\
Hypertension (II0 - II5) & $41.3(57)^{\mathrm{a}}$ \\
Ischemic heart disease (I25) & $16.8(23)^{\mathrm{a}}$ \\
Atherosclerosis (I70) & $42.5(58)^{\mathrm{a}}$ \\
Diabetes (EI0, EII, EI3, EI4) & $45(62)^{\mathrm{a}}$ \\
Cerebrovascular disease (I64, I65, I66, 169) & $10.9(15)^{\mathrm{a}}$ \\
Degenerative polyarthritis (MI5-MI9) & $77.9(107)^{\mathrm{a}}$ \\
Mental disorders (F03; F06.3; F06.7) & $51.7(71)^{\mathrm{a}}$ \\
Diseases of the senses constituted (H 25, & $65.1(89)^{\mathrm{a}}$ \\
H53, H80, H90) & \\
\hline Nes: & \\
\hline
\end{tabular}

Notes: Data are presented as ${ }^{a} \mathrm{n}(\%) ;{ }^{b}$ mean \pm SD, median. ${ }^{\#}$ Values do not add up due to the possibility of multiple choice of answers.

Abbreviations: II0, essential (primary) hypertension; III, hypertensive heart disease; II2, hypertensive renal disease; II3, hypertensive heart and renal disease; II5, secondary hypertension; 125 , chronic ischemic heart disease; EI0, type I diabetes mellitus; EII, type 2 diabetes mellitus; EI3, other specified diabetes mellitus; EI4, unspecified diabetes mellitus; 164, stroke, not specified as hemorrhage or infarction; 165 , occlusion and arteries, not resulting in cerebral infarction; 169, sequelae of cerebrovascular disease; MI5, polyarthrosis; MI6, coxarthrosis; MI7, gonarthrosis; MI8, arthrosis of first carpometacarpal joint; MI9, other arthrosis; F03, unspecified dementia; F06.3, organic mood (affective) disorders; F06.7, mild cognitive disorder; $\mathrm{H} 25$, senile cataract; $\mathrm{H} 53$, visual disturbances, $\mathrm{H} 80$, otosclerosis; $\mathrm{H} 90$, conductive and sensorineural hearing loss. $\beta=0.174 ; p<0.001$; and depressive disorders in care-receivers GDS $\beta=0.178 ; p<0.001$. However, it is worth noticing that ICs' QoL is strongly dependent and positive or directly proportional to the support provided by others, and weak and negatively dependent or inversely proportional to experience in care and depressive disorders (the GDS) in care-receivers, as well as weak and directly proportional to caregivers' health self-assessment.

\section{Discussion}

Caregivers' QoL is measured by means of different tools depending on the methodological research assumptions, for example, the type of disease or severity of disability. In our study, caregivers' QoL was assessed with the WHOQoL-AGE designed especially for the assessment of aging populations. ${ }^{46}$

According to the WHOQoL-AGE, the mean value of overall caregivers' QoL is higher than those by Zawisza et al, ${ }^{39}$ who obtained 58.6 ( $\mathrm{SD}=14.8)$. In our study, higher $\mathrm{QoL}$ can result from caregivers' younger age ( $\mathrm{M}=68.57$ years old) than those in the research by Zawisza et $\mathrm{al}^{39}(\mathrm{M}=76.1$ years old). The report by Santos et al ${ }^{47}$ aimed at checking comparability of the WHOQoL-AGE results in three European countries with 3,940 Polish participants, the QoL score was the highest in Finland in comparison with Spain and Poland.

In our study, spouses were the most common caregivers then children. In the research by Kosińska et al, ${ }^{26}$ caregivers of individuals qualified for long-term home care took care of predominantly their parents and parents-in-law, spouse and individuals of further kinship. In Poland, children are slightly more frequently involved in care (from $54 \%$ in the group of severely disabled care-receivers to $44 \%$ in the group of the least disabled) in comparison with Greece, Germany, Sweden, Great Britain, and Italy (49-52\%, respectively). ${ }^{30}$ 
WHOQOL-AGE

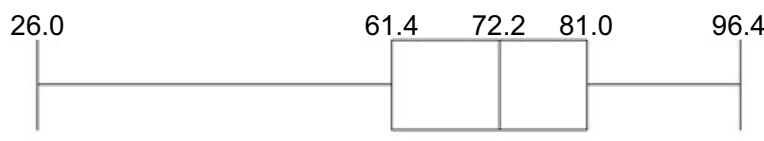

Subscale F1 satisfaction

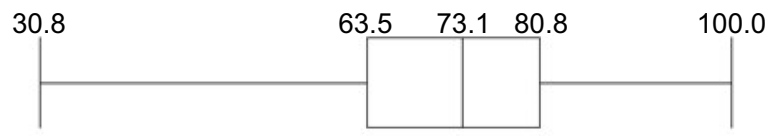

Subscale F2 expectations fulfilment
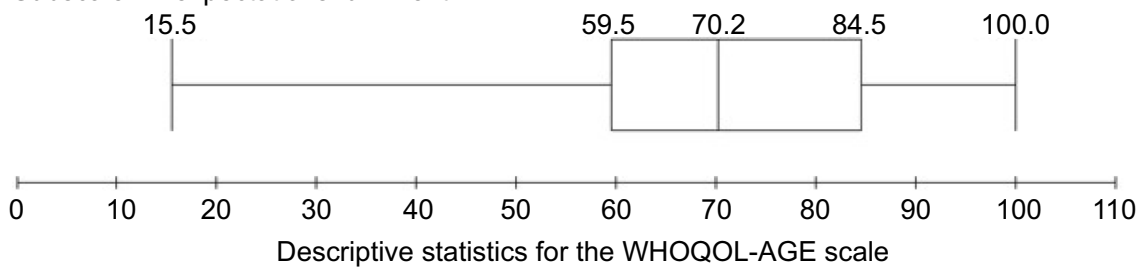

Figure 2 Quartile box plots for the WHOQoL-AGE scale.

Abbreviations: $\mathrm{FI}$, subscale of satisfaction WHOQoL-AGE scale; F2, subscale of expectations fulfilment WHOQoL-AGE scale.

Table 3 Model of selected conditions of IC's QoL consistent with the WHOQoL-Age in home care provided for individuals with chronic diseases and a functional performance deficit

\begin{tabular}{|c|c|c|c|c|c|c|c|c|}
\hline \multicolumn{9}{|l|}{ Variable (WHOQoL-AGE) } \\
\hline \multirow[t]{2}{*}{ Model } & \multicolumn{3}{|c|}{ Goodness of fit } & \multicolumn{5}{|c|}{ Regression weights for predictors } \\
\hline & $R^{2}$ adjusted & $\boldsymbol{F}$ & $p$-value & B & SE (B error) & $\beta$ (Beta) & $t$ & $p$-value \\
\hline Step I & & & & & & & & \\
\hline Support provided by others & 0.373 & 71.693 & 0.000 & 3.114 & 0.368 & 0.615 & 8.467 & 0.000 \\
\hline Step 2 & & & & & & & & \\
\hline Support provided by others & 0.404 & 41.345 & 0.000 & 3236 & 0.361 & 0639 & 8.956 & 0.000 \\
\hline Experience in care & & & & 4.928 & 1.834 & -0.192 & -2.687 & 0.008 \\
\hline Step 3 & & & & & & & & \\
\hline Support provided by others & 0.431 & 31.107 & 0.000 & 3.085 & 0.358 & 0.609 & 8.626 & 0.000 \\
\hline Experience in care & & & & 5.140 & 1.793 & -0.200 & -2.866 & 0.005 \\
\hline ICs' health self-assessment & & & & 2.416 & 0.937 & 0.181 & 2.577 & 0.011 \\
\hline Step 4 & & & & & & & & \\
\hline Support provided by others & 0.459 & 26.207 & 0.000 & 3.066 & 0.349 & 0.605 & 8.781 & 0.000 \\
\hline Experience in care & & & & 5.651 & 1.761 & -0.220 & -3.209 & 0.002 \\
\hline IC's health self-assessment & & & & 2.325 & 0.915 & 0.174 & 2.540 & 0.012 \\
\hline Depressive symptoms in care-receivers & & & & 0.699 & 0.268 & -0.178 & -2.612 & 0.010 \\
\hline
\end{tabular}

Notes: Variables introduced in step I: SP $\left[F(1.118)=71.693 ; p<0.001\right.$ and adjusted $\left.R^{2}=0.373\right]$. Variables introduced in step 2: SP CE $[F(2.117)=41.345 ; p<0.001 ;$ adjusted $R^{2}=0.404$ and $R^{2}$ change $\left.=0.036\right]$. Variables introduced in step 3: SP_CE_CHSA $\left[F(3.116)=31.107 ; p<0.001\right.$; adjusted $R^{2}=0.431$, and $R^{2}$ Change $\left.=0.032\right]$. Variables introduced in step 4: SP_CE_CHSA_GDS-SF $\left[F(4.115)=26.207 ; p<0.001\right.$; adjusted $R^{2}=0.459$ and $R^{2}$ change $\left.=0.03 \mathrm{I}\right] . R^{2}$, coefficient of determination; $F$, sum of squared regression; $\mathrm{B}$, unstandardized regression coefficient; SE (B error), error of unstandardized regression coefficient; $\beta$ (Beta), standardized regression coefficient; $t$, Student's $t$-test; $p$, significance level. GDS-SF measures depressive symptoms in care-receivers.

Abbreviations: IC, informal caregiver; SP, support provided by others; CE, experience in care; CHSA, IC' health self-assessment; GDS-SF, Geriatric Depression Scale Short Form.

Providing informal services of long-term home care for a family member is deeply rooted in the Polish culture. The tradition of taking care of parents by their children, mainly daughters, is still very strong, particularly in rural areas.
Females frequently serve as caregivers twice: at the age of 30-40 when they look after their offspring, and then at the age of 50-60 when they take care of their parents and parents-inlaw $^{48}$ and lastly they provide care for their husbands. 
Therefore, caregivers can be said to acquire experience in caring for consecutive family members. Similarly, in our study, most caregivers took care of a subsequent person. The perception of traditional family roles and obligation of caregiving in Poland is similar to the tradition in Eastern and Southern Europe, ${ }^{19}$ which is confirmed in the results of the European project Eurofamcare. ${ }^{49}$ They show that ICs are mainly women (76\%) mean age of 55 years old, who are married $(22 \%)$, having their own children or adopted ones $(60 \%)$, living in the same household or building as their patients $(56 \%)$. The intensity and duration of their care were $46 \mathrm{hrs}$ weekly, and the mean duration of care was 60 months (5 years). In our study, the mean number of hours devoted weekly by a caregiver was lower and amounted to slightly less than $34.78 \mathrm{hrs}$ and the mean duration of care for a care-receiver was shorter and equaled 3.59 years $(\mathrm{SD}=2.68)$. Vitaliano et $\mathrm{al}^{50}$ emphasize that the longer the duration of care, the worse the caregivers' somatic condition, which makes them more prone to negative effects of stress.

Predictive ability of multidimensional factors of the assessment of ICs'QoL was examined in our study. The analysis indicated that, among numerous factors, four predictors were significantly important: support given to caregivers, experience in care, caregivers' health self-assessment and depressive symptoms in care-receivers, which explained $46 \%$ of variance of dependent variable (the WHOQoL-AGE) in four successive steps of the model created.

ICs' experience in care of patients and support provided by others are two strongest factors of ICs' QoL. Programmes of support for ICs can potentially improve the results of both ICs' and care-receivers' QoL. Many programmes for ICs are implemented in different systems of care, for instance, the National Family Caregiver Support Program and Older Americans Act in the USA. ${ }^{8}$ In Poland, the support system of family caregivers is realized in public long-term care in the system of social welfare (social welfare homes, community self-help homes) and in health care system (nursing institutions, therapeutic and nursing institutions) as well as home care. Home care includes nursing services for bedridden patients and those with chronic diseases but not requiring hospital stay who have considerable deficits in self-care and obtained $<40$ points in the Barthel scale. ${ }^{19,51}$ Despite the development of many formal forms of support for family caregivers, the need for new ones is still growing. Moreover, support tools for ICs are being developed by nurses, for example, those within the project "We will cope with them". This project offers educational
Internet platform, films, manuals, workshops for caregivers all over Poland. ${ }^{52}$

Both the studies by Bleijlevensa et $\mathrm{al}^{53}$ and Rodriguesa et $\mathrm{al}^{54}$ highlight that ICs in home care feel a worse QoL in comparison with ICs of patients being provided with institutional care. Therefore, it is worth mentioning that support of ICs is of great significance in the context of subjective, more positive assessment of their health condition and QoL. ${ }^{55,56}$

Another important correlate of QoL is ICs' health. Most of the ICs researched assessed their health condition as good and had satisfaction in care. Our results are consistent with two major meta-analyses concentrated on physical burden of ICs that show lack of harmful influence on physical health related to care. ${ }^{50,57}$ The results obtained are also similar to research encompassing greater and more representative population of caregivers that support the Healthy Caregiver Hypothesis. ${ }^{14,58-62}$ The results can be connected to the Healthy Caregiver Hypothesis that was proposed as an alternative paradigm for explaining positive health effects linked to carrying out the role of a caregiver. According to the hypothesis, older adults who have become caregivers have better health results than those who have never been caregivers. ${ }^{63,64}$

An aspect of negative significance for QoL of ICs is the presence of depressive disorders among care-receivers. Lower functional performance of care-receivers caused by chronic diseases and intensifying cognitive and depressive disorders due to their age negatively affects QoL of caregivers and care-receivers. ${ }^{65-70}$

Longer duration of care is associated with greater burden and the occurrence of depressive symptoms and anxiety ${ }^{71}$ which leads to worse health self-assessment and lower caregiver's QoL. The research by Rodrigues et $\mathrm{al}^{54}$ confirms that the longer an individual is an IC, the lower the scoring of QoL and the worse his or her health selfassessment.

The meta-analysis by Pinquart and Sörensen ${ }^{57}$ showed that there is a significant impact (negative correlation) of the following predictive factors: caregiver's age, spouse as a caregiver, number of hours devoted to care, number of caring duties, duration of care and care-receiver's physical, behavioural and cognitive problems, on the deterioration of caregivers' physical health and self-assessment. However, caregivers' physical health improves along with an increase in informal support (positive correlation). Literature presents evidence of care-giving's negative effect on the caregivers' physical health, which is 
associated with high level of burden ${ }^{14}$ and psychic stress as well as the occurrence of depression in caregivers. $^{72,73,74}$

\section{Research limitations}

The research has some limitations. Firstly, the participants were recruited from the local community of ICs in home care so they are not country representatives. The crosssurvey project of the research and analysis of results obtained limit the research power to its causal conclusions. Secondly, the research results are based on a not very large group, which can be significant in the generalization of the results obtained. A supplementary prospective longitudinal study would be recommended to show comparison with caregivers of individuals provided with institutional care.

\section{Practical implications}

Due to an increase in the Polish population of the elderly with chronic diseases and diminished functional performance, there is a greater need for the implementation of additional trainings for ICs on skills of using new technology such as the Internet, mobile phone, or telemedicine that could support them psycho educationally and emotionally. The implementation of the WHOQol - AGE as screening is worth considering for nurses in order to assess ICs' QoL. For better assessment of ICs' caring activity, the measurement of quality of informal care is recommended by creating appropriate media of quality of informal care, for instance, search for support, psychological skills and clinical knowledge.

The role of nurses is of great significance in the scope of trainings for ICs concerning care for care-receivers with chronic diseases and improvement of their functional performance at home. Additional social support in care given to IC should be charitable and based on cooperation with local governments and religious groups.

\section{Conclusions}

The results of our study show that main factors that determine almost by half QoL of ICs who look after the elderly in their home environment are support in care given by others, ICs' experience in care, ICs' health self-assessment and depressive symptoms in care-receivers. The support in care given to ICs, ICs' higher health self-assessment and ICs' experience in care constitute essential determinants that are prognostically positive for QoL. Intensifying symptoms of depression in care-receivers in home care are a negative correlate of ICs' QoL. The aforementioned determinants should be taken into consideration to plan systems supporting home care provided by ICs.

\section{Compliance with ethical standards Ethical approval}

The study was approved by the Bioethics Commission of the Medical University of Lublin (ethical approval number KE-0254/13/2016).

\section{Informed consent}

All caregivers and care-receivers who participated in the study signed an informed consent form before enrolment.

\section{Acknowledgments}

This study was funded by the Medical University of Lublin, Poland (grant number DS-519).

\section{Disclosure}

The authors declare that they have no conflicts of interest in this work.

\section{References}

1. European Commission Directorate-General for Economic and Financial Affairs. The 2015 ageing report economic and budgetary projections for the $28 \mathrm{EU}$ Member States (2013-2060). Econ Finan Aff. 2015;3:399. Available from: http://ec.europa.eu/economy_finance/ publications/european_economy/2015/pdf/ee3_en.pdf.

2. Eurostat newsrelease. Population projections 2010-2060. EU27 population is expected to peak by around 2040. One person in eight aged 80 or more in 2060. Population. Available from: http://ec.europa.eu/euro stat/documents/2995521/5039334/3-08062011-BP-EN.PDF/fad284a674eb-4eb6-9e6c-f29331b875f0. Accessed May 25, 2018.

3. Czekanowski P. The aging process of societies and the family situation of old people. Sociol Rev. 2013;62(2):55-78.

4. Beck O, Kędziora-Kornatowska K, Kornatowski M. Long-term home care in Poland - framework, problems, prospects. Hygeia Public Health. 2014;49(2):192-196.

5. Ryan AA, McCann S, McKenna H. Impact of community care in enabling older people with complex needs to remain at home. Int J Older People Nurs. 2009;4(1):22-32. doi:10.1111/j.1748-3743.2008.00152.x

6. Verbeek H, Meyer G, Leino-Kilpi H, et al. A European study investigating patterns of transition from home care towards institutional dementia care: the protocol of a RightTimePlaceCare study. BMC Public Health. 2012;12:68. doi:10.1186/1471-2458-12-68

7. Hiel L, Beenackers MA, Renders CM, et al. Providing personal informal care to older European adults: should we care about the caregivers' health? Prev Med. 2015;70:64-68. doi:10.1016/j. ypmed.2014.10.028

8. Van Houtven $\mathrm{CH}$, Voils CI, Weinberger M. An organizing framework for informal caregiver interventions: detailing caregiving activities and caregiver and care recipient outcomes to optimize evaluation efforts. BMC Geriatr. 2011;11:77. doi:10.1186/1471-2318-11-77

9. Musich S, Wang SS, Kraemer S, Hawkins K, Wicker E. Caregivers for older adults: prevalence, characteristics, and health care utilization and expenditures. Geriatr Nurs. 2017;38(1):9-16. doi:10.1016/j. gerinurse.2016.06.017 
10. Furmańska-Maruszak A. Work and eldercare balance. Support for informal elderly carers in the labour market international comparisons. Acta Universitatis Lodziensis Folia Oeconomica. 2015;2(312):111-126.

11. Eurofamcare. Services for supporting family carers of of elderly people in Europe: characteristics, coverage and usage. Summary of main findings from Eurofamcare. Available from: https://www.uke. de/extern/eurofamcare/. Accessed May 20, 2018.

12. Grabowska-Fudala B, Jaracz K, Smelkowska A, et al. The burden of caregivers of patients with Alzheimer's disease. Preliminary results. Now Lek. 2013;82(1):25-30.

13. Ganapathy V, Graham GD, DiBonaventura MD, et al. Caregiver burden, productivity loss, and indirect costs associated with caring for patients with poststroke spasticity. Clin Interv Aging. 2015;10:1793-1802.

14. Roth DL, Haley WE, Hovater M, Perkins M, Wadley VG, Judd S. Family caregiving and all-cause mortality: findings from a population-based propensity-matched analysis. Am J Epidemiol. 2013;178(10):1571-1578. doi:10.1093/aje/kwt225

15. Rosochacka-Gmitrzak M. Support for informal carers - towards the balance of social expectations and caring abilities of familie. In: Racław M, editor. Public Care, Private Care. Local Communities Towards the Elderly. Warsaw: Institute of Public Affairs; 2011:95-140.

16. Huber M, Rodrigues R, Hoffmann F, Gasior K, Marin B. Facts and Figures on Long-Term Care. Europe and North America, Occasional Reports Series 6. Vienna: European Center; 2009.

17. Furmańska-Maruszak A, Wójtewicz A. The directions of development of long-term care services in Poland. Studia Oeconomica Posnaniensia. 2016;4(9):28-42. doi:10.18559/SOEP.2016.9.2

18. Szweda-Lewandowska Z. Models of care for dependent persons. Econ Stud. 2014;179:215-224.

19. World Bank. Current status and future of long-term care in an aging Poland. 2015. Available from: http://www.niesamodziel nym.pl/uploads/Bank\%20\%C5\%9Awiatowy\%20Opieka_dlugoter minowa.pdf.

20. Czekanowski P. Family in the lives of the elderly people and the elderly people in the family. In: Synak B, editor. Polish Aging. Gdansk: Publishing House University of Gdansk; 2002:163-167.

21. Błedowski P, Pedich W Services for supporting family carers of elderly people in Europe: characteristics, coverage and usage. National background report for Poland. Available from: http://www. monitoringris.org/documents/tools_nat/nabare/nabare_poland_rc1_ a4.pdf Accessed May 20, 2018.

22. Szatur-Jaworska B. The forms of family life among older people. In: Błędowski P, editor. Medical, Psychological, Sociological and Economic Aspects of the Aging People in Poland. Warsaw: Warsaw School of Economics Institute of Labour and Social Studies in Warsaw; 2011:12-17.

23. Ziomek-Michalak K. Role of the family in the ageing process and the man's perception of old age. Annal Theol. 2015;62(10):175-194.

24. Wóycicka I, Rurarz R. Demand for care. In: Kotowska IE, Sztanderska U, Wóycicka I, editors. Professional and Educational Activity in Consideration of Family Responsibilities. Warsaw: Scholar; 2007:269-282.

25. Gawlik M, Kurpas D. Evaluation of caregivers' quality of life in patients with cancer with the use of the Caregiver Quality of LifeCancer questionnaire. Palliat Med. 2015;7(1):67-77.

26. Kosińska M, Kułagowska E, Niebrój L, Stanisławczyk D. Burdens of caregivers of patients classified for long-term home care. Environ Med. 2013;16(2):59-68.

27. Ciałkowska-Kuźmińska M, Kasprzak M. Caregivers' burden as a factor of nursing home admission. Polish J Geriatr Psychiatry. 2012;9(2):69-76.
28. Zysnarska M, Wojnicz-Michera I, Taborowska M, Kołecki P, Maksymiuk T. Woman - a carer for a chronically-ill person - determinants of overload. Now Lek. 2010;79(5):386-391.

29. Kosmala K, Kloszewska I. The burden of providing care for Alzheimer's disease patients in Poland. Int $J$ Geriatr Psychiatry. 2004;19:191-193. doi:10.1002/gps.1054

30. Bień B, Wojszel ZB, Doroszkiewicz H. Level of disability of older persons as indication for supporting of family caregivers. Polish Gerontol. 2008;16(1):25-34.

31. Marczak M, Tasak A. Expectations of patients and their guardians regarding nursing care system provided to chronically ill patients at home. Polit Zdrow. 2008/2009;7:77-81.

32. Abramczyk A. Expectations of family circles/guardians of diabetics within the scope of education in diabetes - in the light of nationwide research. Environ Med. 2013;16(1):58-66.

33. Karczewska B, Bień B, Ołdak E, Jemiołkowski J. Family caregivers of older people with dementia or cognitive disorders in Poland - risk factors of care burden. Polish Gerontol. 2012;20(2):59-67.

34. Grochowska J. Feeling of satisfaction and being burdened with duties among informal care givers of the elderly according to the level of efficacy of care recipients. Med Og Nauki Zdr. 2014;20(1):46-50.

35. Reinhard SC, Given B, Petlick NH, Bemis A. Supporting family caregivers in providing care. In: Hughes RG, editor. Patient Safety and Quality: An Evidence-Based Handbook for Nurses. Rockville (MD): Agency for Healthcare Research and Quality (US); 2008:146. Available from: https://www.ncbi.nlm.nih.gov/books/NBK2665/.

36. Kim H, Chang M, Rose K, Kim S. Predictors of caregiver burden in caregivers of individuals with dementia. $J$ Adv Nurs. 2012;68 (4):846-855. doi:10.1111/j.1365-2648.2011.05787.x

37. Rachel W, Datka W, Zyss T, Zięba A. The influence of long-term care on the health of caregivers of Alzheimer's disease patients. Przegl Lek. 2014;71(12):703-706.

38. Caballero FF, Miret M, Power M, et al. Validation of an instrument to evaluate quality of life in the aging population: WHOQOL-AGE. Health Qual Life Outcomes. 2013;11:177. doi:10.1186/1477-7525$11-83$

39. Zawisza K, Gałaś A, Tobiasz-Adamczyk B. Validation of the Polish version of the WHOQOL-AGE scale in older population. Polish Gerontol. 2016;24:7-16.

40. Mahoney FI, Barthel DW. Functional evaluation: the Barthel Index A simple index of independence useful in scoring improvement in the rehabilitation of the chronically ill. Md State Med J. 1965;14:61-65.

41. Kuźmicz I, Brzostek T, Górkiewicz M. Barthel questionnaire as measurement tool for physical independence of older adults. Med Stud. 2008;12:17-21.

42. Romanik W, Łazarewicz M. The Polish version of the Abbreviated Mental Test Score (AMTS) - methodology issues. J Psychiatr Clin Psychol. 2017;17(3):203-207.

43. Albiński R, Kleszczewska-Albińska A, Bedyńska S. Geriatric Depression Scale (GDS). Validity and reliability of different versions of the scale - review. Pol Psychiatr. 2011;45(4):555-562.

44. Yesavage JA, Brink TL, Rose TL, et al. Development and validation of a geriatric depression screening scale: a preliminary report. J Psychiatr Res. 1982;17(1):37-49.

45. Bedyńska S, Książek M. Statistical Guideline 3 - Practical Guide for the Use of Regression Models and Structural Equations. Warsaw: College of Social Psychology; 2012.

46. Fang J, Power M, Lin Y, Zhang J, Hao Y, Chatterji S. Development of short versions for the WHOQOL-OLD module. Gerontologist. 2012;52(1):66-78. doi:10.1093/geront/gnr085

47. Santos D, Abad FJ, Miret M, et al. Measurement invariance of the WHOQOL-AGE questionnaire across three European countries. Qual Life Res. 2018;27(4):1015-1025. doi:10.1007/s11136-017$1737-8$ 
48. Kotowska IE, Wóycicka I Caring for care and other conditions for increasing the professional activity of people at older working age. Research report. Department of Economic Analysis and Forecasts Ministry of Labor and Social Policy. Available from: http://www. analizy.mpips.gov.pl/images/stories/publ_i_raporty/sprawowanie_ opieki.pdf. Accessed May 21, 2018.

49. Eurofamcare. Examples of good and innovative practices in supporting family carers in Europe; February 2006: 41. Available from: https://www.uke.de/extern/eurofamcare/. Accessed May 20, 2018.

50. Vitaliano PP, Zhang J, Scanlan JM. Is caregiving hazardous to one's physical health? A meta-analysis. Psychol Bull. 2003;129 (6):946-972. doi:10.1037/0033-2909.129.6.946

51. Working Group for the Preparation of the Non-Alliance Risk Insurance Act at the Senators Club of the Civic Platform: Longterm care in Poland. Description, diagnosis, recommendations. Available from: http://rszarf.ips.uw.edu.pl/kierunki/ODzielona.pdf. Accessed May 21, 2018

52. Assumptions of the "We will cope with them" project. Available from: https://damy-rade.info/o-projekcie. Accessed May 21, 2018.

53. Bleijlevens MH, Stolt M, Stephan A, et al. Changes in caregiver burden and health-related quality of life of informal caregivers of older people with Dementia: evidence from the European RightTimePlaceCare prospective cohort study. J Adv Nurs. 2015;71 (6):1378-1391. doi:10.1111/jan.12561

54. Rodrigues AM, Ferreira PL, Ferré-Grau C. Providing informal home care for pressure ulcer patients: how it affects carers' quality of life and burden J Clin Nurs. 2016;25(19-20):3026-3035. doi:10.1111/jocn.13356

55. Basińska MA, Lewandowska PN, Kasprzak A. Social support and fatigue of everyday life of the caregivers of people with Alzheimer's diseas. Polish J Geriatr Psychiatry. 2013;10(2):49-58.

56. Głębocka A, Szarzyńska M. Social support and well-being among the elderly. Polish Gerontol. 2005;13(4):255-259.

57. Pinquart M, Sörensen S. Correlates of physical health of informal caregivers: a meta-analysis. J Gerontol B Psychol Sci Soc Sci. 2007;62(2):126-137. doi:10.1093/geronb/62.2.P126

58. Chappell NL, Dujela C. Caregiving: predicting at-risk status. Can J Aging. 2008;27(2):169-179. doi:10.3138/cja.27.2.169

59. Brown SL, Smith DM, Schulz R, et al. Caregiving behavior is associated with decreased mortality risk. Psychol Sci. 2009;20 (4):488-494. doi:10.1111/j.1467-9280.2009.02323.x

60. Buyck JF, Bonnaud S, Boumendil A, et al. Informal caregiving and self-reported mental and physical health: results from the Gazel Cohort Study. Am J Public Health. 2011;101(10):1971-1979. doi:10.2105/AJPH.2010.300044

61. Fisher GG, Frank MM, Plassman BL, et al. Caring for individuals with dementia and CIND: findings from the Aging, Demographics, and Memory Study. J Am Geriatr Soc. 2011;59(3):488-494. doi:10.1111/j.1532-5415.2010.03304.x

62. Jones SL, Hadjistavropoulos HD, Janzen JA, Hadjistavropoulos T. The relation of pain and caregiver burden in informal older adult caregivers. Pain Med. 2011;12(1):51-58. doi:10.1111/j.15264637.2010.01018.x
63. Fredman L, Cauley JA, Satterfield S, et al. Caregiving, mortality, and mobility decline: the Health, Aging, and Body Composition (Health ABC) Study. Arch Intern Med. 2008;168(19):2154-2162. doi:10.1001/archinte.168.19.2154

64. Bertrand RM, Saczynski JS, Mezzacappa C, et al. Caregiving and cognitive function in older women: evidence for the healthy caregiver hypothesis. J Aging Health. 2012;24(1):48-66. doi:10.1177/ 0898264311421367

65. Yikılkan H, Aypak C, Görpelioğlu S. Depression, anxiety and quality of life in caregivers of long-term home care patients. Arch Psychiatr Nurs. 2014;28(3):193-196. doi:10.1016/j. apnu.2014.01.001

66. Robison J, Fortinsky R, Kleppinger A, Shugrue N, Porter M. A broader view of family caregiving: effects of caregiving and caregiver conditions on depressive symptoms, health, work, and social isolation. J Gerontol B Psychol Sci Soc Sci. 2009;64 (6):788-798. doi:10.1093/geronb/gbp015

67. Mittelman MS, Ferris SH, Shulman E, et al. A comprehensive support program: effect on depression in spouse-caregivers of $\mathrm{AD}$ patients. Gerontologist. 1995;35(6):792-802.

68. Covinsky KE, Newcomer R, Fox P, et al. Patient and caregiver characteristics associated with depression in caregivers of patients with dementia. J Gen Intern Med. 2003;18(12):1006-1014.

69. McPherson CJ, Wilson KG, Chyurlia L, Leclerc C. The balance of give and take in caregiver-partner relationships: an examination of self-perceived burden, relationship equity, and quality of life from the perspective of care recipients following stroke. Rehabil Psychol. 2010;55(2):194-203. doi:10.1037/a0019359

70. Pinquart M, Sörensen S. Associations of caregiver stressors and uplifts with subjective well-being and depressive mood: a meta-analytic comparison. Anging Ment Health. 2004;8(5):438-439. doi:10.1080/13607860410001725036

71. Castora-Binkley M, Noelker LS, Ejaz FK, Rose M. Inclusion of caregiver supports and services in home-and community-based service programs: recent reports from state units on aging. $J$ Aging Soc Policy. 2011;23(1):19-33. doi:10.1080/ 08959420.2011 .532001

72. Jowsey T, McRae I, Gillespie J, Banfield M, Yen L. Time to care? Health of informal older carers and time spent on health related activities: an Australian survey. BMC Public Health. 2013;13 (1):374-384. doi:10.1186/1471-2458-13-374

73. Chow EO, Ho HC. The relationship between psychological resources, social resources, and depression: results from older spousal caregivers in Hong Kong. Aging Ment Health. 2012;16 (8):1016-1027. doi:10.1080/13607863.2012.692769

74. Adelman RD, Tmanova LL, Delgado D, Dion S, Lachs MS. Caregiver burden: A clinical review. JAMA. 2014;311 (10):1052-1060. doi:10.1001/jama.2014.304 


\section{Supplementary materials}

Table SI Selection process primary health care settings

\begin{tabular}{|l|l|l|l|}
\hline $\begin{array}{l}\text { Primary } \\
\text { health care }\end{array}$ & $\begin{array}{l}\text { Number of dyads chosen based on } \\
\text { the criteria assumed }\end{array}$ & $\begin{array}{l}\text { Number of dyads included in } \\
\text { the random study }\end{array}$ & $\begin{array}{l}\text { Number of nurses col- } \\
\text { lecting the data }\end{array}$ \\
\hline PHC-1 & 56 & 27 & 3 \\
PHC-2 & 72 & 32 & 4 \\
PHC-3 & 83 & 41 & 4 \\
PHC-4 & 68 & 32 & 4 \\
PHC-5 & 47 & 23 & 3 \\
TOTAL & 324 & 155 & 18 \\
\hline
\end{tabular}

Note: PHC refers to primary health care settings, with numbers I-4 referring to settings in urban areas, and number 5 referring to a setting in a rural area.

Table S2 WHOQoL-AGE variables excluded in the model

\begin{tabular}{|c|c|c|c|c|}
\hline \multirow[t]{2}{*}{ Model } & \multicolumn{4}{|l|}{ Regression weights for predictors } \\
\hline & Partial correlation coefficient & $\beta$ (Beta) & $\boldsymbol{t}$ & $\mathbf{p}$ \\
\hline \multicolumn{5}{|l|}{ Step I } \\
\hline Sex & -0.035 & -0.028 & $-0,379$ & 0,706 \\
\hline Age & -0.141 & -0.111 & $-1,535$ & 0,127 \\
\hline Civil status & -0.021 & -0.017 & $-0,227$ & 0,821 \\
\hline Relation to patient & -0.002 & -0.002 & $-0,023$ & 0,982 \\
\hline Distance from the caregiver's place of residence to the patient's & -0.067 & -0.053 & $-0,731$ & 0,466 \\
\hline Health self-assessment & 0.215 & 0.172 & 2,376 & 0,019 \\
\hline Experience in care & -0.241 & -0.192 & $-2,687$ & 0,008 \\
\hline Duration of care of a patient & -0.108 & -0.091 & $-1,174$ & 0,243 \\
\hline Support provided by other people & 0.093 & 0.075 & 1,014 & 0,313 \\
\hline Abbreviated Mental Test Score (AMTS) & 0.051 & 0.042 & 0,557 & 0,578 \\
\hline Geriatric Depression Scale - Short Form (GDS-SF) & -0.203 & -0.160 & $-2,244$ & 0,027 \\
\hline Barthel index & 0.135 & 0.114 & 1,468 & 0,145 \\
\hline \multicolumn{5}{|l|}{ Step 2} \\
\hline Sex & -0.059 & -0.046 & -0.642 & 0.522 \\
\hline Age & -0.126 & -0.097 & -1.371 & 0.173 \\
\hline Civil status & -0.013 & -0.010 & -0.138 & 0.890 \\
\hline Relation to patient & -0.044 & -0.034 & $-0.47 \mid$ & 0.639 \\
\hline Distance from the caregiver's place of residence to the patient's & -0.057 & -0.043 & -0.611 & 0.542 \\
\hline Health self-assessment & 0.233 & 0.181 & 2.577 & 0.011 \\
\hline Duration of care of a patient & -0.104 & -0.086 & $-1.13 \mid$ & 0.260 \\
\hline Support provided by other people & 0.054 & 0.043 & 0.578 & 0.564 \\
\hline Abbreviated Mental Test Score (AMTS) & 0.096 & 0.078 & 1.044 & 0.299 \\
\hline Geriatric Depression Scale - Short Form (GDS-SF) & -0.239 & -0.184 & -2.649 & 0.009 \\
\hline Barthel index & 0.174 & 0.144 & 1.898 & 0.060 \\
\hline \multicolumn{5}{|l|}{ Step 3} \\
\hline Sex & -0.050 & -0.038 & -0.541 & 0.590 \\
\hline Age & -0.080 & -0.061 & $-0.86 \mid$ & 0.391 \\
\hline Civil status & 0.016 & 0.012 & 0.173 & 0.863 \\
\hline
\end{tabular}

(Continued) 
Table S2 (Continued).

\begin{tabular}{|c|c|c|c|c|}
\hline \multirow[t]{2}{*}{ Model } & \multicolumn{4}{|c|}{ Regression weights for predictors } \\
\hline & Partial correlation coefficient & $\beta$ (Beta) & $t$ & $\mathbf{p}$ \\
\hline Relation to patient & -0.019 & -0.014 & -0.202 & 0.840 \\
\hline Distance from the caregiver's place of residence to the patient's & -0.053 & -0.039 & -0.569 & 0.571 \\
\hline Duration of care of a patient & 0.088 & 0.076 & 0.943 & 0.348 \\
\hline Support provided by other people & -0.096 &,- 077 & -1.037 & 0.302 \\
\hline Abbreviated Mental Test Score (AMTS) & 0.103 & 0.081 & 1.112 & 0.269 \\
\hline Geriatric Depression Scale - Short Form (GDS-SF) & 0.073 & 0.058 & 0.787 & 0.433 \\
\hline Barthel index & -0.237 & -0.178 & -2.612 & 0.010 \\
\hline \multicolumn{5}{|l|}{ Step 4} \\
\hline Sex & -0.067 & -0.049 & -0.715 & 0.476 \\
\hline Age & -0.102 & -0.076 & -1.100 & 0.274 \\
\hline Civil status & -0.023 & -0.017 & -0.250 & 0.803 \\
\hline Relation to patient & -0.093 & -0.072 & -0.992 & 0.323 \\
\hline Distance from the caregiver's place of residence to the patient's & -0.016 & -0.012 & -0.171 & 0.864 \\
\hline Duration of care of a patient & -0.106 & -0.083 & -1.144 & 0.255 \\
\hline Support provided by other people & 0.116 & 0.089 & 1.252 & 0.213 \\
\hline Abbreviated Mental Test Score (AMTS) & 0.029 & 0.023 & 0.314 & 0.754 \\
\hline Barthel index & 0.086 & 0.071 & 0.926 & 0.356 \\
\hline
\end{tabular}

Notes: Coding - Sex: I - female; 2 - male. Age: I - $\leq 68$ years; 2 - >68 years. Civil status: I - single; 2 - married/in a relationship. Relation to patient: I - spouse/partner and parents; 2 - other (sibling/child, daughter-in-law/son-in-law, further family, lack of kinship/friend/neighbor). Distance from the caregiver's place of residence to the patient's: I the same flat, the same building, a short-walk distance); 2 - about 10-minute distance by means of transportation, about 30-minute distance by means of transportation, about 60-minute distance by means of transportation, over 60-minute distance by means of transportation. Health self-assessment: 2 - very good, good; I - mediocre, poor, very poor. Experience in care: I- the first person being taken care of; 2 - a consecutive person being taken care of. Duration of care of a patient: I - $\leq 3.59$ years; 2 - >3.59 years. Support provided by other people: I - lack of support; 2 - support provided. Abbreviated Mental Test Score (AMTS): I - $\leq 7.78 ; 2$ - >7.78 Geriatric Depression Scale Short Form (GDS-SF): I - $\leq 7.34 ; 2$ - >7.34. Barthel index: I - $\leq 43.2 ; 2$ - >43.2.

\section{Publish your work in this journal}

Clinical Interventions in Aging is an international, peer-reviewed journal focusing on evidence-based reports on the value or lack thereof of treatments intended to prevent or delay the onset of maladaptive correlates of aging in human beings. This journal is indexed on PubMed Central, MedLine, CAS, Scopus and the Elsevier
Bibliographic databases. The manuscript management system is completely online and includes a very quick and fair peer-review system, which is all easy to use. Visit http://www.dovepress.com/ testimonials.php to read real quotes from published authors. 